\title{
Black Zirconia-Graphene Nanocomposite Produced by Spark Plasma Sintering
}

\author{
N.W. Solis ${ }^{1}$, P. Peretyagin ${ }^{1, \text { a) }}$, A. Seleznev ${ }^{1}$, R. Torrecillas ${ }^{1,2}$, J. S. Moya ${ }^{3, \text { b) }}$ \\ ${ }^{1}$ Moscow State University of Technology "STANKIN", 1 Vadkovsky lane, Moscow, 127994, Russian Federation. \\ ${ }^{2}$ Nanomaterials and Nanotechnology Research Centre (CINN) (CSIC-Universidad de Oviedo), 33940 El Entrego, \\ Principado de Asturias, Spain. \\ ${ }^{3}$ Centro de Investigación en Nanomateriales y Nanotecnología - CINN (Consejo Superior de Investigaciones \\ Cientificas-Universidad de Oviedo-Principado de Asturias) Avenida de la Vega 4-6, 33940 El Entrego \\ (San Martín del Rey Aurelio) Asturias (España). \\ ${ }^{a}$ Corresponding author: p.peretyagin@stankin.ru \\ b)jsmoya@icmm.csic.es
}

\begin{abstract}
In this work, 3Y-TZP/graphene composites are prepared by Spark Plasma Sintering of zirconia-graphene oxide mixtures. Simultaneous sintering and in-situ reduction of graphene oxide opens a very interesting technological route for preparing this type of materials. The influence of graphene content on the electrical, mechanical and optical properties is studied. Graphene content as low as 0.29 vol\% allows obtaining nanostructured black zirconia, but it has to be increased up to $1 \mathrm{vol} \%$ in order to reach electrical resistivity $<100 \Omega \mathrm{cm}$, as it is required for electro discharge machining.
\end{abstract}

\section{INTRODUCTION}

Yttria stabilized zirconia is widely used as a structural material in machinery due to its superior properties, such as high strength, high hardness, and high toughness [1-3]. After sintering in oxidizing conditions, pure dense zirconia has a white color. Therefore, many studies have been performed up today for the diversification of the zirconia color [4-9]. In this regard, the black color has attracted many research works due to a wide range of possible high added-value applications, i.e. artificial jewelry, luxury watches, knifes, bearing balls, optical devices, fiber optics components or PVD targets. Most of the black zirconia commercial products are fabricated by adding 2 to $10 \mathrm{wt} \%$ black pigments as $\mathrm{CoFe} 2 \mathrm{O} 4$ spinel to the starting 3YTZP tetragonal submicrometer powder and subsequent sintering in the temperature interval ranging from $1400{ }^{\circ} \mathrm{C}$ to $1600{ }^{\circ} \mathrm{C}$.

In many of the above mentioned applications, the presence of metals like $\mathrm{Co}$ and $\mathrm{Fe}$ is not appropriate due to technical requirements, i.e. PVD targets, inductive charging system, or health problems as allergy to Co, etc. Additionally, these commercial materials are not electrical conductors and EDM cannot be used for machining.

On the other hand, zirconia has a very low thermal conductivity. This fact has a limitation in the size of the components to be fabricated by conventional processing routes. Advanced sintering technologies as HP also have limitations concerning the maximum thickness of the samples to be pressed, as heat has to be transferred from the mould to the sample. Spark plasma sintering has also limitations due to the high heating rates used during sintering and, as a consequence, important temperature gradients take place along the sample. In fact, SPS open a new possibility for electric conductive materials, as, additionally to the heating process by the mould, conductive powders can be heated up by the Joule effect during sintering. SPS seems to be only useful for the case of conductive materials, and the most part of ceramics cannot take profit of the advantages of this interesting sintering technology.

The use of carbon nanostructures, such as carbon nanotubes (CNTs) and carbon nanofibers (CNFs), as additives for preparing electroconductive ceramics has been profusely studied. Nevertheless, the difficulty for getting good

Mechanics, Resource and Diagnostics of Materials and Structures (MRDMS-2016)

AIP Conf. Proc. 1785, 040074-1-040074-5; doi: 10.1063/1.4967131

Published by AIP Publishing. 978-0-7354-1447-1/\$30.00 
dispersions of CNTs and CNFs in ceramic matrices has limited the progress in this research line. Since the discovery of graphene, efforts have been focused on the use of this carbon nanostructure as the reinforcement phase in ceramic matrices. In this sense, graphene oxide has several key advantages versus graphene regarding its processing, such as i) it can be obtained through a low cost method in high quantities (Kg.), ii) as any oxide, it can be homogeneously dispersed in water, and, consequently, iii) mixtures of any ceramic oxide and graphene oxide can be processed following conventional ceramics processing routes. On the top of this, with a small volume fraction of graphene, it is possible to reach the percolation threshold in the bulk sample to become a conductor material.

In the present study we fabricate theoretical dense electroconductive poreless black zirconia compacts by adding a small fraction of graphene oxide. The obtained compacts are characterized mechanically and electrically. This new functionality (electrical-thermal conductivity) enables one to use SPS avoiding the limitations derived from the low thermal conductivity of zirconia and also allows the machining of complex-shaped components by electro-discharge machining methods (EDM).

\section{EXPERIMENTAL}

The starting materials were $\mathrm{ZrO}_{2}$ (3YTZP, Tosoh Corp., Japan) with the average particle size of $180 \mathrm{~nm}$ and Graphene oxide synthesized from synthetic graphite by the modified Hummers method. A colloidal method was used to prepare the GO/3YTZP powders. $40 \mathrm{~g}$ of 3 YTZP were added into $100 \mathrm{~mL}$ of water where the pH was previously fixed to 10 by adding $\mathrm{NH}_{4} \mathrm{OH}$. The 3 YTZP powder was dispersed under stirring for $30 \mathrm{~min}$. Then, the suspension of graphene oxide was dropwise added in order to prepare the desired composition. The mixed powders were kept stirred for $1 \mathrm{~h}$. Then, the suspension was dried in a Lab Spray drier (Nano Spray Dryer B-90 Advanced, Buchi) at an exit temperature of $110^{\circ} \mathrm{C}$. The obtained powders were ready to press mixtures.

The powder samples were placed into a graphite die with an inner diameter of $20 \mathrm{~mm}$ and uniaxially pressed cold at $20 \mathrm{MPa}$. Then, they were introduced in an SPS apparatus KCE-FCT-H-HP-D25-SD (FCT Systeme, Rauenstein, Germany) under low vacuum $\left(10^{-1} \mathrm{mbar}\right)$ and sintered at $1400^{\circ} \mathrm{C}$ for 1 min under an applied pressure of $80 \mathrm{MPa}$ and a heating rate of $100^{\circ} \mathrm{C} / \mathrm{min}$. The bulk density of the sintered bodies was measured by the Archimedes method using water as a solvent.

Vickers hardness was measured by using a Micrometer 5103 (Buehler) durometer, loading $300 \mathrm{~g}$ for $10 \mathrm{~s}$ and making 30 measurements per sample. The microstructure was studied by field emission scanning electron microscopy, FESEM (FEI: Quanta FEG 650). The dielectric properties of the samples were studied by standard lowfrequency impedance measurements (PSM1735-NumetriQ) in the $0.1 \mathrm{~Hz}$ to $1 \mathrm{kHz}$ frequency range. The color of the disks was also analyzed with the use of a spectrophotometer apparatus (Konica Minolta CM-700d model), which is based on the CIE standard light source of D65 as a light source, with a measurement area of $8 \mathrm{~mm}$. The surface finish of all samples was polished down to $1 \mu \mathrm{m}$ with a sample thickness of $3 \mathrm{~mm}$ approximately. The final results were an average of four readings on each disk.

\section{RESULTS AND DISCUSSION}

The addition of carbon second phases to ceramics has several effects in terms of processing. Thus, during the powder packing step at the beginning of the SPS process, the graphene oxide sheets can acts as a lubricant favoring the appropriate zirconia grains sliding to reach the optimum packing. Nevertheless, the incorporation of carbon second phases will make difficult the composite densification. In this sense, the Spark Plasma Sintering technique, which applies pressure while heating, is a very suitable technology for preparing this type of composites. Sintering temperature was selected by following the piston displacement during heating until the piston movement was stopped. Figure 1 shows the microstructures of zirconia composites with 0.29 and $0.39 \mathrm{wt} \%$ graphene oxide contents as examples.

The SPS process is carried out in reducing conditions, vacuum and graphite environment, and the GO is reduced to pure graphene. The zirconia grain size on the microstructure of the zirconia + graphene SPS compacts is significantly affected by the presence of graphene. Graphene is not observed due to the low content added, but its presence is inferred from its pinning effect on zirconia grain boundaries avoiding grain growth. Completely dense materials are obtained, the average grain size of zirconia being very similar to the starting powder with the biggest grains below $0.5 \mu \mathrm{m}$. Then, small additions of GO $(<0.5 \mathrm{wt} \%)$ in combination with Spark Plasma Sintering allow obtaining dense materials without significant grain growth.

Figure 2 presents the electrical conductivity of $\mathrm{ZrO}_{2}$-graphene composites. 
It is clearly shown that the percolation threshold takes place between 0.8 and $1 \mathrm{wt} \%$ graphene oxide. Samples with graphene contents below $1 \mathrm{wt} \%$ graphene (only $0.8 \mathrm{wt} \%$ graphene is shown for clarity) show conductivity values close to that of the pure YSZ, whereas a gap of 8 orders of magnitude in conductivity is found on increasing the graphene content up to $1 \%$. The electrical behavior of percolated samples is also different from that of unpercolated samples. Percolated samples show a conductivity plateau, which corresponds to the dc conductivity of the percolated graphene network, whereas the conductivity of the un-percolated samples increases with the frequency due to polarization between neighboring conductive clusters. Over $1 \%$ graphene content, the conductivity of the samples gradually increases, but in much smaller gaps, due to the increase of the vol. content of the conductive phase. Then, it has been determined that the minimum content for reaching the necessary low resistivity to be machined by using EDM technologies is around $1 \mathrm{wt} \%$. We will see now that the mechanical properties of the obtained zirconia + graphene SPS compacts with a that low content of GO addition in order to be electrical conductive are not significantly affected.

Table 1 shows the density and Vickers Hardness of ZrO2-GO composites.

ZrO2-Graphene composites show slightly lower hardness values than monolithic zirconia. This can be attributed to the presence of a carbon phase, which is a comparatively softer material.

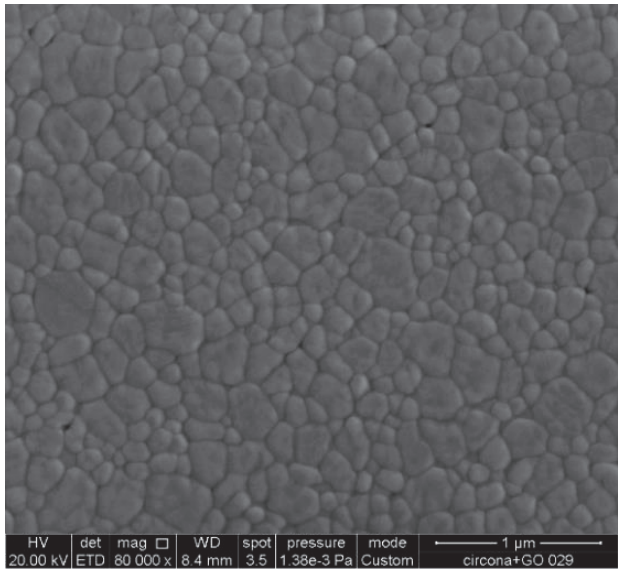

$0.29 \mathrm{wt} \% \mathrm{GO}$

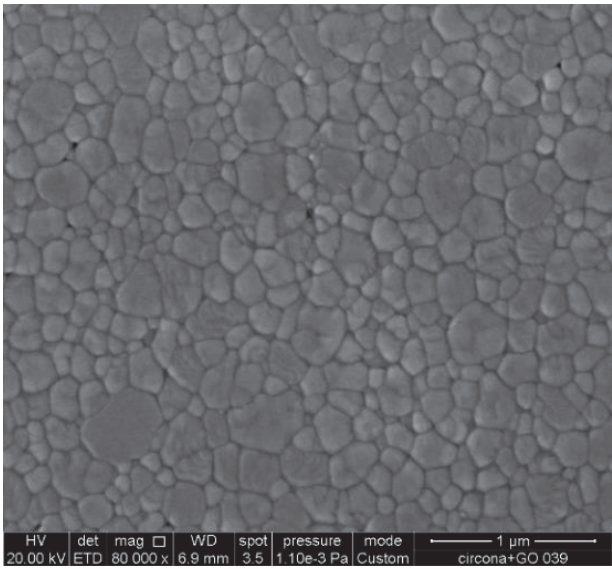

$0.39 \mathrm{wt} \% \mathrm{GO}$

FIGURE 1. Microstructures of $\mathrm{ZrO} 2-(0.29 \mathrm{wt} \%) \mathrm{GO}$ and $\mathrm{ZrO} 2-(0.39 \mathrm{wt} \%) \mathrm{GO}$ composites

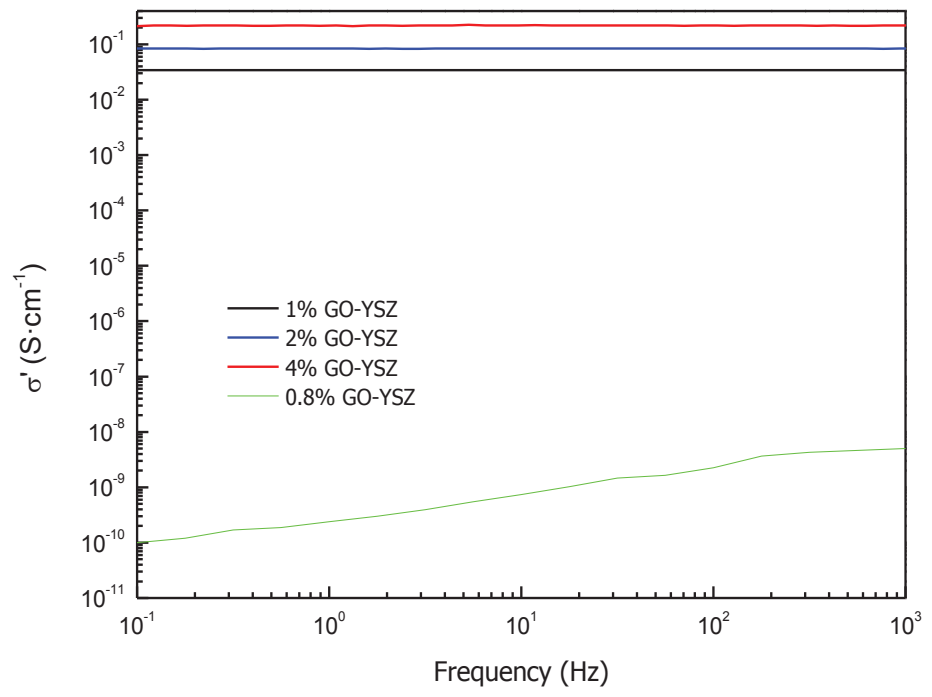

FIGURE 2. Low frequency conductivity of $\mathrm{ZrO} 2$-graphene composites 
TABLE 1. Density and hardness of $\mathrm{ZrO} 2$-graphene composites

\begin{tabular}{lcccc}
\hline \multirow{2}{*}{ Properties } & \multicolumn{4}{c}{ GO content $(\mathbf{w t} \%)$} \\
\cline { 2 - 5 } & $\mathbf{0}$ & $\mathbf{0 . 3}$ & $\mathbf{0 . 4}$ & $\mathbf{1 . 0}$ \\
\hline Density $\left(\mathrm{g} / \mathrm{cm}^{3}\right)$ & 6.01 & 6.02 & 6.00 & 6.01 \\
Hardness HV10 $(\mathrm{GPa})$ & 12.97 & 12.44 & 12.56 & 12.50 \\
\hline
\end{tabular}

Finally, blackness measurements were carried out comparing three samples: pure 3Y-TZP zirconia ("white" zirconia), commercial "black" zirconia from Tosoh and the 3Y-TZP-1wt\%-GO composite. Table 2 shows the values obtained for $\mathrm{L}^{*} \mathrm{a}^{*} \mathrm{~b}^{*}$ parameters.

TABLE 2. The whiteness index of the zirconia-GO composite in comparison with commercial white and black

\begin{tabular}{|c|c|c|c|}
\hline & $\mathbf{L}$ & $\mathbf{a}$ & $\mathbf{B}$ \\
\hline Commercial "White" zirconia & 88.56 & 0.14 & 2.15 \\
\hline Commercial "Black" zirconia & 44.39 & 0.01 & -0.96 \\
\hline ZrO2-1wt\%GO composite & 36.44 & 0.23 & 0.57 \\
\hline
\end{tabular}

The value of $\Delta \mathrm{L}$ is increased by $18 \%$ when it is compared with the commercial black zirconia obtained by addition of $\mathrm{Co} 3 \mathrm{O} 4$.

In summary, this new family of zirconia-graphene nanocomposites is fully dense materials, free of metals (Co, $\mathrm{Fe}$ ); they reach a blackness value better than commercial black zirconia materials preserving zirconia hardness, and they can be machined by EDM thanks to their low electrical resistivity. Consequently, they could find a great number of new applications, e. g., in the production of wear resistant components, as well as in the field of biomaterials, where complex-shaped components are required.

\section{CONCLUSIONS}

Black zirconia with the blackness index higher than that of commercial products based on metals can be obtained by a small addition of graphene. The low content of graphene allows maintaining the mechanical properties of zirconia, such as hardness.

Graphene-zirconia composites can be easily processed by starting form graphene oxide and performing in-situ reduction during Spark Plasma Sintering. When the graphene content is increased up to 1 wt $\%$, the electrical resistivity of the composite is lower than $100 \Omega \mathrm{cm}$, and this allows electrodischarge machining to be used for making complex shapes from these materials, which are demanded by many applications.

\section{ACKNOWLEDGMENTS}

We would like to thank the Ministry of Education of the Russian Federation for supporting this work under contract No.14.577.21.0089, unique identifier of contract RFMEFI57714X0089.

\section{REFERENCES}

1. M. H. Bocanegra-Bernal, S. D. De La Torre, Journal of Materials Science 37 (23), 4947-4971 (2002).

2. C. F. Gutiérrez-González, M. Suarez, S. Pozhidaev, S. Rivera, P. Peretyagin, W. Solís, L. A. Díaz, A. Fernandez, R. Torrecillas, Journal of the European Ceramic Society 36 (8), 2149-2152 (2016).

3. J. R. Kelly, I. Denry, Dental Materials 24 (3), 289-298 (2008).

4. $\quad$ K.-H. Lee, Y.-S. Lee, J.-S. Park, B.-H. Lee, Journal of the Korean Ceramic Society 45 (4), 214-219 (2008).

5. E. Sani, L. Mercatelli, J.-L. Sans, D. Sciti, Solar Energy Materials and Solar Cells (available online) (2014).

6. A. Metel, V. Bolbukov, M. Volosova, S. Grigoriev, Y. Melnik, Instruments and experimental techniques $\mathbf{5 7}$ (3), 345-351 (2014).

7. S. N. Grigoriev, A. S. Metel, S. V. Fedorov, Metal Science and Heat Treatment 54 (1-2), 8-12 (2012).

8. L. A. Díaz, M. A. Montes-Morán, P. Y. Peretyagin, Yu. G. Vladimirov, A. Okunkova, J. S. Moya, R. Torrecillas, Journal of Nanoparticle Research 16 (2), 2257 (2014) 
9. E. Fernandez-Garcia, C. F. Gutierrez-Gonzalez, R. Torrecillas, A. Fernandez, P. Peretyagin, W. Solis, S. Lopez-Esteban, Materials Science and Engineering: A 646, 96-100 (2015). 